\title{
Clinical significance of decoy receptor 3 upregulation in patients with hepatitis $B$ and liver fibrosis
}

\author{
XIAOLI LOU, YANQIANG HOU, HUI CAO, JINGJING ZHAO and FENGTING ZHU \\ Department of Central Laboratory, Songjiang Hospital Affiliated First People's Hospital, \\ Shanghai Jiao Tong University, Shanghai 201600, P.R. China
}

Received September 28, 2017; Accepted April 16, 2018

DOI: $10.3892 / \mathrm{ol} .2018 .8762$

\begin{abstract}
Decoy receptor 3 (DcR3) is a tumor necrosis factor receptor, which may inhibit apoptosis. The aim of the present study was to investigate the clinical significance of DcR3 upregulation in patients with chronic hepatitis $\mathrm{B}$ (CHB) and hepatic fibrosis. A total of 128 patients with a clinical diagnosis of CHB who underwent liver biopsy were included in the present study. The expression levels of DcR3, hyaluronic acid (HA), type III procollagen, type IV collagen (IV-C) and laminin protein were assessed. The diagnostic value of DcR3 in patients with $\mathrm{CHB}$ with hepatic fibrosis was determined using receiver operating characteristic (ROC) curve analysis. DcR3 was significantly upregulated in patients with $\mathrm{CHB}$, particularly in patients with active CHB. The expression of DcR3 was significantly increased in patients with $\mathrm{CHB}$ with liver fibrosis and liver cirrhosis, compared with patients with $\mathrm{CHB}$ without liver fibrosis. The area under the ROC curve for the diagnosis of CHB liver fibrosis based on DcR3 or DcR3 combined with IV-C/HA was 0.807 or 0.869 , with a sensitivity and specificity of 76.9 and $77.8 \%$ or 84.6 and $81.2 \%$, respectively. DcR3 is a marker for liver fibrosis in patients with hepatitis B infection. The use of DcR3 in combination with IV-C and HA may further increase its diagnostic value for liver fibrosis.
\end{abstract}

\section{Introduction}

Chronic viral hepatitis $\mathrm{B}(\mathrm{CHB})$ poses a serious threat to human health. An epidemiological study demonstrated that the seroprevalence rate of hepatitis B virus surface antigen in the Chinese population is $7.18 \%$ (1). Hepatitis B may lead to hyperplasia of hepatic fibrous connective tissues, resulting in liver fibrosis and cirrhosis $(2,3)$. Detection of hepatitis B

Correspondence to: Dr Yanqiang Hou, Department of Central Laboratory, Songjiang Hospital Affiliated First People's Hospital, Shanghai Jiao Tong University, 748 Middle Zhongshan Road, Shanghai 201600, P.R. China

E-mail: houyanqiang@aliyun.com

Key words: decoy receptor 3, chronic hepatitis B, liver fibrosis, receiver operating curve virus (HBV) DNA is the most common laboratory method for the evaluation of virus replication activity. Alanine aminotransferase (ALT), aspartate aminotransferase (AST) and $\gamma$-glutamyl transferase $(\gamma$-GGT) are serum indicators of liver function in patients with CHB. Hyaluronic acid (HA), type III procollagen (PCIII), type IV collagen (IV-C) and laminin protein (LN) are commonly used as indicators of liver fibrosis (4-6). However, these indicators do not completely meet the clinical requirements due to their limited sensitivity and specificity (7). Pathological examination by liver biopsy, which carries a risk of complications, is required for the diagnosis of liver fibrosis (8-10). Thus, it is required to identify noninvasive markers of liver fibrosis with clinical diagnostic or therapeutic significance. Decoy receptor 3 (DcR3), a novel member of the tumor necrosis factor receptor (TNFR) superfamily, is a surface receptor that competitively binds Fas Ligand (FasL), lymphotoxin-related inducible ligand that competes for glycoprotein D binding to herpesvirus entry mediator on T cells (LIGHT) and TNF-like ligand 1A (TL1A) ligands to inhibit apoptosis. It has been indicated that the expression of DcR3 is increased in the inflammatory response to bacterial infection, rheumatoid arthritis, acute ulcerative colitis and appendicitis, and in tumors (11). DcR3 is closely associated with cancer and inflammation (12). The aim of the present study was to examine the expression of DcR3 in patients with hepatitis B and hepatic fibrosis and to explore its clinical diagnostic value.

\section{Materials and methods}

Study subjects. A total of 128 patients (male, $\mathrm{n}=72$; female, $\mathrm{n}=56$; median age, 38 years; range, $20-65$ years) diagnosed with CHB were recruited in The Liver Department of Songjiang Hospital Affiliated to First People's Hospital (Shanghai, China) between December 2014 and December 2015. All patients with $\mathrm{CHB}$ met the criteria for the diagnosis of $\mathrm{CHB}$ published in 'Chronic HBV Hepatitis Treatment and Prevention Guide' (13). Patients with a history of fatty liver, alcoholic liver disease, obesity, liver cancer, hepatitis $\mathrm{C}$, hepatitis $\mathrm{D}$, autoimmune liver disease and other liver diseases, as well as those with a recent history of infection and allergy were excluded. All patients provided written informed consent. All procedures were performed in compliance with the relevant provisions of the Ethics Committee of Songjiang District Center Hospital 
(Shanghai, China). The control group consisted of 50 healthy individuals admitted for physical examination who had no recent history of infection, autoimmunity or other diseases, and who had normal indicators in the physical examination. The healthy control patients also provided written informed consent and this process was approved by the ethics committee. Blood samples in the case and control groups were collected and centrifuged at $1,006.2 \mathrm{xg}$ for $10 \mathrm{~min}$ at $4^{\circ} \mathrm{C}$. Serum samples were separated and stored at $-80^{\circ} \mathrm{C}$ for later use.

Serum biomarker detection. Serum level of DcR3 was detected using a Human DcR3 ELISA kit (ELH-DcR3, RayBiotech, Inc., Norcross, GA, USA). Serum levels of HA, PCIII, IV-C and LN were determined using Human ELISA kits (CSB-E04805h, 11989h, 17116h, 16273h, CusaBio, Wuhan, China). The kits were performed according to manufacturer's protocols. Serum HBV DNA was measured using an ABI7500 system (Thermo Fisher Scientific, Inc., Waltham, MA, USA), and ALT, AST and $\gamma$-GGT were detected using the Roche automatic biochemical analyzer (Roche Diagnostics, Indianapolis, IN, USA). Interleukin-6 (IL-6) and PCT levels were determined using luminscence with a Cobas e601 instrument (Roche, Basle, Switzerland).

Histopathological examination of liver biopsy tissues and experimental grouping. Liver biopsy specimens were fixed using $10 \%$ neutral formalin for at least $2 \mathrm{~h}$ at room temperature, embedded in paraffin and cut into 3-4 $\mu \mathrm{m}$ sections, which were then subjected to routine hematoxylin and eosin (H\&E) staining using Hematoxylin and Eosin Staining kit (C0105; Beyotime Institute of Biotechnology, Nanjing, China). Collagenous connective tissue fibers were stained using Godon and Sweet reticular fiber stain kit (YDJ4105; Yuduo Biotech, Shanghai, China) and Trichrome Stain (Masson) kit (HT15; Sigma-Aldrich; Merck KGaA, Darmstadt, Germany). The staining procedure followed the manufacturer's protocols. Sections were examined by two or more physicians and classified as $\mathrm{S}_{0}-\mathrm{S}_{4}$ according to the degree of liver fibrosis as follows: $\mathrm{S}_{0}$, no fibrosis; $\mathrm{S}_{1-3}$, gradual increase in the degree of fibrosis; and $\mathrm{S}_{4}$, liver cirrhosis. The negative control (NC) group consisted of the healthy individuals. Patients with CHB with ALT $>40$ IU/l, HBV DNA>105 copies/ml were classified as active CHB and included in the present study. The remaining patients were classified as patients who are CHB carriers.

Bioinformatics andstatistical analysis. Bioinformatics analysis was performed using Oncomine software (Oncomine ${ }^{\mathrm{TM}}$ V4.5 online; https://www.oncomine.com/resource/login. $\mathrm{html}$ ) to analyze differences in DcR3 expression in the human hepatocellular carcinoma (HCC) DNA microarray database (https://www.oncomine.com/resource/login.html). Differences between two independent samples were analyzed using the independent samples Student's t-test (Table I) and SPSS 20.0 software (IBM Corp., Armonk, NY, USA). The mean differences between numerous samples were analyzed using Kruskal-Wallis and an analysis of variance, with Dunn's multiple comparison test as a post-hoc. Levene's Test was used to analyze the Equality of Variances. Receiver operating characteristic (ROC) curve analysis was performed. The correlations between DcR3 and HBV DNA, ALT, AST,
GGT, HA, IV-C, PCIII, LN, or NF- $\kappa \mathrm{B}$ were analyzed using Pearson's correlation test. The gender difference was analyzed using a $\chi^{2}$ test. $\mathrm{P}<0.05$ was considered to indicate a statistically significant difference. All the data are presented as median and ranges or mean \pm standard error.

\section{Results}

$D c R 3$ expression is significantly increased in patients with CHB. Serum DcR3 levels $(196.88 \pm 26.67 \mathrm{ng} / \mathrm{ml})$ were significantly higher in the CHB group, compared with the healthy control group $(0.047 \pm 0.006 \mathrm{ng} / \mathrm{ml} ; \mathrm{P}<0.05$; Table I). In addition, $\gamma$-GGT, AST and ALT levels were significantly higher in the CHB group, compared with the healthy control group $(\mathrm{P}<0.05$; Table I). However, there was no significant difference in procalcitonin and interleukin 6 between the two groups, which demonstrated similar responses to acute inflammation. The serum levels of HA, PCIII, IV-C and LN were significantly higher in the CHB group, compared with the control group $(\mathrm{P}<0.05$; Table I).

DcR3 expression is significantly increased in patients with active hepatitis $B$. Patients with CHB with ALT $>40 \mathrm{IU} / 1$, HBV DNA $>10^{5}$ copies $/ \mathrm{ml}$ were classified as active hepatitis B group (active $\mathrm{CHB}$ ). The remaining patients who did not meet any of these criteria were classified as hepatitis B carriers (CHB carrier). Serum DcR3 levels were significantly higher in the active CHB group $(253.82 \pm 32.12 \mathrm{ng} / \mathrm{ml})$, compared with the CHB carrier group $(151.35 \pm 12.03 \mathrm{ng} / \mathrm{ml}$; P $<0.05$; Fig. 1).

$D c R 3$ levels are increased in patients with hepatitis $B$ and liver fibrosis. Patients with CHB were divided into three groups according to pathology results: $\mathrm{S}_{0}, \mathrm{CHB}$ group without fibrosis group; $\mathrm{S}_{1-3}$, CHB group complicated with fibrosis group; and $\mathrm{S}_{4}$, group with cirrhosis. $\mathrm{NC}$ was the healthy control group. The results demonstrated that the DcR3 levels were significantly higher in the $\mathrm{S}_{1-3}$ group $(227.37 \pm 18.71 \mathrm{ng} / \mathrm{ml})$ and the $\mathrm{S}_{4}$ group $(355.26 \pm 5.054 \mathrm{ng} / \mathrm{ml})$, compared with the $\mathrm{S}_{0}$ group $(109.66 \pm 16.08 \mathrm{ng} / \mathrm{ml})$. DcR3 levels were significantly higher in the $\mathrm{S}_{4}$ group $(355.26 \pm 5.054 \mathrm{ng} / \mathrm{ml})$, compared with the $S_{1-3}$ group (227.37 $\pm 18.71 \mathrm{ng} / \mathrm{ml}$; Fig. 2). The levels of HA, PCIII, IV-C and LN were significantly higher in the $\mathrm{S}_{1-3}$ and $\mathrm{S}_{4}$ groups, compared with the $\mathrm{S}_{0}$ group $(\mathrm{P}<0.05$; Table II).

Significant association between DcR3 and fibrosis indicators. Results demonstrated that DcR3 levels were significantly increased in the hepatic fibrosis group $\left(\mathrm{S}_{1-4}\right)$ and significantly associated with the four indicators of hepatic fibrosis: HA ( $\mathrm{r}=0.51, \mathrm{P}<0.001)$; IV-C ( $\mathrm{r}=0.34, \mathrm{P}=0.0013)$; PCIII ( $\mathrm{r}=0.49$, $\mathrm{P}<0.001)$; and $\mathrm{LN}(\mathrm{r}=0.40, \mathrm{P}<0.001)$. In addition, serum DcR3 levels in patients with CHB were positively associated with HBV DNA, ALT, AST and GGT levels $(r=0.27,0.53,0.54$ and 0.48 , respectively; $\mathrm{P}<0.001$; Table III). However, DcR3 levels had no association with sex and age in patients with CHB.

Diagnostic value of DcR3 in CHB and hepatic fibrosis. The diagnostic ability of DcR3 and liver fibrosis indicators (IV-C, HA, PCIII and LN) for CHB with hepatic fibrosis was evaluated using ROC curve analysis (Fig. 3), with area under the curve (AUC) values of $0.807,0.770,0.688,0.626$ and 0.584 , 
Table I. Clinical data of patients with CHB infection and healthy controls (mean \pm standard error).

\begin{tabular}{|c|c|c|c|c|c|c|}
\hline \multirow[b]{2}{*}{ Characteristic } & \multirow[b]{2}{*}{ Control $(n=60)$} & \multirow[b]{2}{*}{$\mathrm{CHB}(\mathrm{n}=128)$} & \multicolumn{2}{|c|}{$\begin{array}{c}\text { Levene's test for } \\
\text { equality of } \\
\text { variances }\end{array}$} & \multirow[b]{2}{*}{ Student's t-test } & \multirow[b]{2}{*}{ P-value } \\
\hline & & & F-value & Sig. & & \\
\hline Median age (range), years & $35(21-63)$ & $38(20-65)$ & & & & \\
\hline Male/female (n) & $36 / 24$ & $72 / 56$ & & & & $\chi^{2}=0.235, P=0.623$ \\
\hline$\gamma$-GGT $(\mathrm{IU} / 1)$ & $13.78 \pm 1.00$ & $48.02 \pm 4.06$ & 35.280 & $<0.001$ & -8.158 & $<0.001$ \\
\hline AST (IU/l) & $13.18 \pm 0.37$ & $94.84 \pm 14.88$ & 25.770 & $<0.001$ & -5.487 & $<0.001$ \\
\hline ALT (IU/1) & $13.06 \pm 0.70$ & $150.65 \pm 22.50$ & 39.322 & $<0.001$ & -6.112 & $<0.001$ \\
\hline PCT (ng/ml) & $0.14 \pm 0.01$ & $0.14 \pm 0.01$ & 27.844 & $<0.001$ & 0.237 & 0.813 \\
\hline IL-6 (pg/ml) & $14.40 \pm 1.32$ & $18.41 \pm 1.43$ & 3.797 & 0.053 & -1.773 & 0.078 \\
\hline $\mathrm{HA}(\mathrm{ng} / \mathrm{ml})$ & $0.57 \pm 0.04$ & $1.00 \pm 0.05$ & 90.94 & 0.014 & -6.330 & $<0.001$ \\
\hline PCIII (ng/ml) & $24.30 \pm 1.34$ & $35.31 \pm 1.39$ & 26.863 & 0.916 & -7.495 & $<0.001$ \\
\hline IV-C (pg/ml) & $475.60 \pm 24.84$ & $819.55 \pm 42.60$ & 6.135 & $<0.001$ & -6.974 & $<0.001$ \\
\hline LN (ng/ml) & $0.08 \pm 0.004$ & $0.11 \pm 0.005$ & 0.011 & 0.0019 & -4.389 & $<0.001$ \\
\hline DcR3 (ng/ml) & $0.24 \pm 0.06$ & $213.01 \pm 14.50$ & 14.519 & $<0.001$ & -14.676 & $<0.001$ \\
\hline
\end{tabular}

$\gamma$-GGT, $\gamma$-glutamyl transferase; AST, aspartate aminotransferase; ALT, alanine aminotransferase; PCT, procalcitonin; IL-6, interleukin 6; HA, hyaluronidase; PCIII, type III procollagen; IV-C, type IV collagen; LN, laminin protein; DcR3, decoy receptor 3; CHB, chronic hepatitis B.

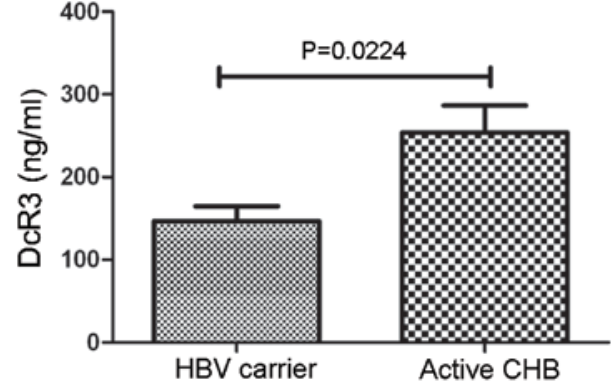

Figure 1. DcR3 level is higher in patients with active CHB $(n=61)$, compared with patients who are CHB carriers $(n=67)$. DcR3 protein concentration was measured using an ELISA kit in patients with active CHB (defined by HBV DNA copy number $>10^{5}$ and alanine aminotransferase $>40$ IU/1) and in CHB carriers. DcR3 was significantly higher in patients with active $\mathrm{CHB}$, compared with in patients who are $\mathrm{CHB}$ carriers $(\mathrm{P}=0.0224)$. $\mathrm{CHB}$, chronic hepatitis B, HBV, hepatitis B virus; DcR3, decoy receptor 3 .

respectively. The $95 \%$ confidence interval, cut-off value, sensitivity and specificity are displayed in Table IV. When the cutoff value for DcR3 was set at $168.67 \mathrm{ng} / \mathrm{ml}$, its diagnostic sensitivity and specificity were 76.9 and $77.8 \%$, respectively (Table IV). When liver fibrosis indicators with improved diagnostic ability, namely IV-C and HA, were used in combination with DcR3 for diagnosis, the AUC for DcR3 combined with IV-C and HA was 0.869 , with sensitivity and specificity of 84.6 and $81.2 \%$, respectively (Table IV). This indicated that DcR3 may significantly improve the combined diagnostic effect of IV-C and HA (AUC of 0.798, with sensitivity and specificity of 71.8 and $75.0 \%$, respectively) and demonstrated the value of DcR3 as a clinical diagnostic index of liver fibrosis.

Nuclear factor (NF)- $\kappa B$ levels are increased in patients with hepatitis $B$ and liver fibrosis. The serum levels of $\mathrm{NF}-\kappa \mathrm{B}$

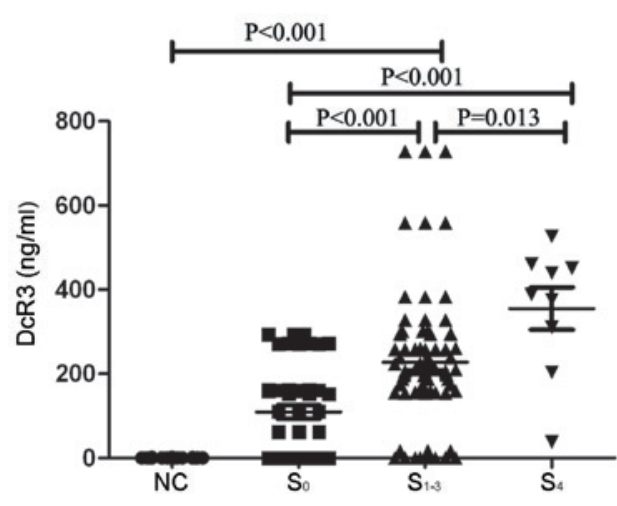

Figure 2. DcR 3 is upregulated in patients with $\mathrm{CHB}$ liver fibrosis and cirrhosis DcR3 levels were significantly higher in $\mathrm{S}_{1-3}$ and $\mathrm{S}_{4}$ groups, compared with in $\mathrm{S}_{0}(\mathrm{P}<0.001)$ or $\mathrm{NC}$ groups $(\mathrm{P}<0.001)$. DcR3 levels were significantly higher in the $\mathrm{S}_{4}$ group, compared with the $\mathrm{S}_{1-3}(\mathrm{P}=0.013)$ group. Patients with $\mathrm{CHB}$ were divided into three groups according to the liver biopsy diagnosis as follows: $S_{0}(n=45)$, CHB without fibrosis; $S_{1-3}(n=74)$, CHB complicated with fibrosis; and $S_{4}(n=9)$, cirrhosis. DcR3, decoy receptor 3; $N C(n=60)$, negative control; CHB $(n=128)$, chronic hepatitis B.

in patients with hepatitis B and liver fibrosis were detected, which demonstrated that $\mathrm{NF}-\kappa \mathrm{B}$ levels were elevated in $\mathrm{S}_{0}(2,128.01 \pm 552,67 \mathrm{pg} / \mathrm{ml}), \mathrm{S}_{1-3}(2,199.50 \pm 460.40)$ and $\mathrm{S}_{4}(2,179.56 \pm 384.11 \mathrm{pg} / \mathrm{ml})$ groups, compared with the control group $(210.33 \pm 53.83 \mathrm{pg} / \mathrm{ml})$ (Fig. 4A). The association between $\mathrm{NF}-\kappa \mathrm{B}$ and DcR3 levels was analyzed, which indicated that there was no association between these two molecules $(r=0.06$, $\mathrm{P}=0.726$; Fig. 4B).

$D c R 3$ mRNA levels are higher in HCC compared with that in normal liver tissues. Analysis of a publicly available human DNA microarray database using Oncomine software indicated that DcR3 mRNA levels are higher in liver cancer 
Table II. Clinical data of patients with CHB liver fibrosis (mean \pm standard deviation).

\begin{tabular}{|c|c|c|c|c|}
\hline Characteristic & $S_{0}(n=45)$ & $\mathrm{S}_{1-3}(\mathrm{n}=74)$ & $\mathrm{S}_{4}(\mathrm{n}=9)$ & P-value \\
\hline Male/female (n) & $20 / 15$ & $41 / 33$ & $6 / 3$ & \\
\hline DcR3 (ng/ml) & $109.66 \pm 16.08$ & $227.37 \pm 18.71^{\mathrm{a} 1}$ & $355.26 \pm 50.54^{\mathrm{a} 2 \mathrm{~b}}$ & $\mathrm{a} 1<0.001, \mathrm{a} 2<0.001, \mathrm{~b}=0.031$ \\
\hline $\mathrm{HA}(\mathrm{ng} / \mathrm{ml})$ & $0.74 \pm 0.060$ & $1.03 \pm 0.05^{\mathrm{a} 1}$ & $1.49 \pm 0.39^{\mathrm{a} 2 \mathrm{~b}}$ & $\mathrm{a} 1=0.003, \mathrm{a} 2<0.001, \mathrm{~b}=0.014$ \\
\hline PCIII (ng/ml) & $22.88 \pm 0.95$ & $35.18 \pm 1.28^{\mathrm{a}}$ & $49.41 \pm 2.41^{\mathrm{b}}$ & $\mathrm{a} 1=0.049, \mathrm{~b}=0.037$ \\
\hline IV-C (pg/ml) & $548.51 \pm 39.33$ & $910.52 \pm 37.40^{\mathrm{a} 1}$ & $1,266.32 \pm 255.32^{\mathrm{a} 2, \mathrm{~b}}$ & $\mathrm{a} 1<0.001, \mathrm{a} 2<0.001, \mathrm{~b}=0.005$ \\
\hline LN (ng/ml) & $0.05 \pm 0.01$ & $0.10 \pm 0.003$ & $0.15 \pm 0.032^{\mathrm{a}, \mathrm{b}}$ & $\mathrm{a}=0.006, \mathrm{~b}=0.002$ \\
\hline$\gamma$-GGT (IU/l) & $23.47 \pm 4.00$ & $51.35 \pm 7.89^{\mathrm{a}}$ & $46.89 \pm 11.69$ & $\mathrm{a}=0.008$ \\
\hline AST (IU/l) & $35.31 \pm 4.50$ & $95.78 \pm 16.09^{\mathrm{a} 1}$ & $176.80 \pm 115.45^{\mathrm{a} 2}$ & $\mathrm{a} 1=0.023, \mathrm{a} 2=0.006$ \\
\hline ALT (IU/1) & $45.26 \pm 5.62$ & $198.72 \pm 35.09^{\mathrm{a}}$ & $186.93 \pm 123.06$ & $\mathrm{a}=0.001$ \\
\hline IL-6 (pg/ml) & $15.33 \pm 1.81$ & $18.01 \pm 2.03$ & $19.91 \pm 5.97$ & \\
\hline PCT (ng/ml) & $0.11 \pm 0.071$ & $0.16 \pm 0.02$ & $0.12 \pm 0.091$ & \\
\hline
\end{tabular}

${ }^{\mathrm{a}} \mathrm{P}<0.05$ vs. $\mathrm{S}_{0}$ group; ${ }^{\text {b }}<0.05$ vs. $\mathrm{S}_{1-3}$ group. $\gamma$-GGT, $\gamma$-glutamyl transferase; AST, aspartate aminotransferase; ALT, alanine aminotransferase; IL-6, interleukin 6; HA, hyaluronidase; PCIII, type III procollagen; IV-C, type IV collagen; LN, laminin; DcR3, decoy receptor 3; CHB, chronic hepatitis B; PCT, procalcitonin.

Table III. Association between DcR3 and other clinical biomarkers.

\begin{tabular}{cccccccccccccc}
\hline Index & Sex & Age & HBV-DNA & $\gamma$-GGT & AST & ALT & HA & PCIII & IV-C & LN & NF- $\kappa B$ \\
\hline DcR3 & $\mathrm{r}=-0.122$ & $\mathrm{r}=-0.355$ & $\mathrm{r}=0.27$ & $\mathrm{r}=0.53$ & $\mathrm{r}=0.54$ & $\mathrm{r}=0.48$ & $\mathrm{r}=0.51$ & $\mathrm{r}=0.49$ & $\mathrm{r}=0.34$ & $\mathrm{r}=0.40$ & $\mathrm{r}=0.06$ \\
& $\mathrm{P}=0.434$ & $\mathrm{P}=0.020$ & $\mathrm{P}<0.001$ & $\mathrm{P}<0.001$ & $\mathrm{P}<0.001$ & $\mathrm{P}<0.001$ & $\mathrm{P}<0.001$ & $\mathrm{P}=0.001$ & $\mathrm{P}=0.0013$ & $\mathrm{P}<0.001$ & $\mathrm{P}=0.726$
\end{tabular}

$\gamma$-GGT, $\gamma$-glutamyl transferase; AST, aspartate aminotransferase; ALT, alanine aminotransferase; HA, hyaluronidase; PCIII, type III procol-

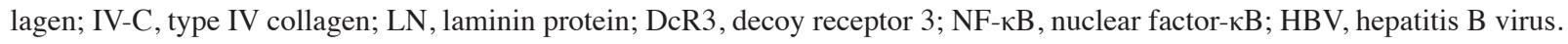
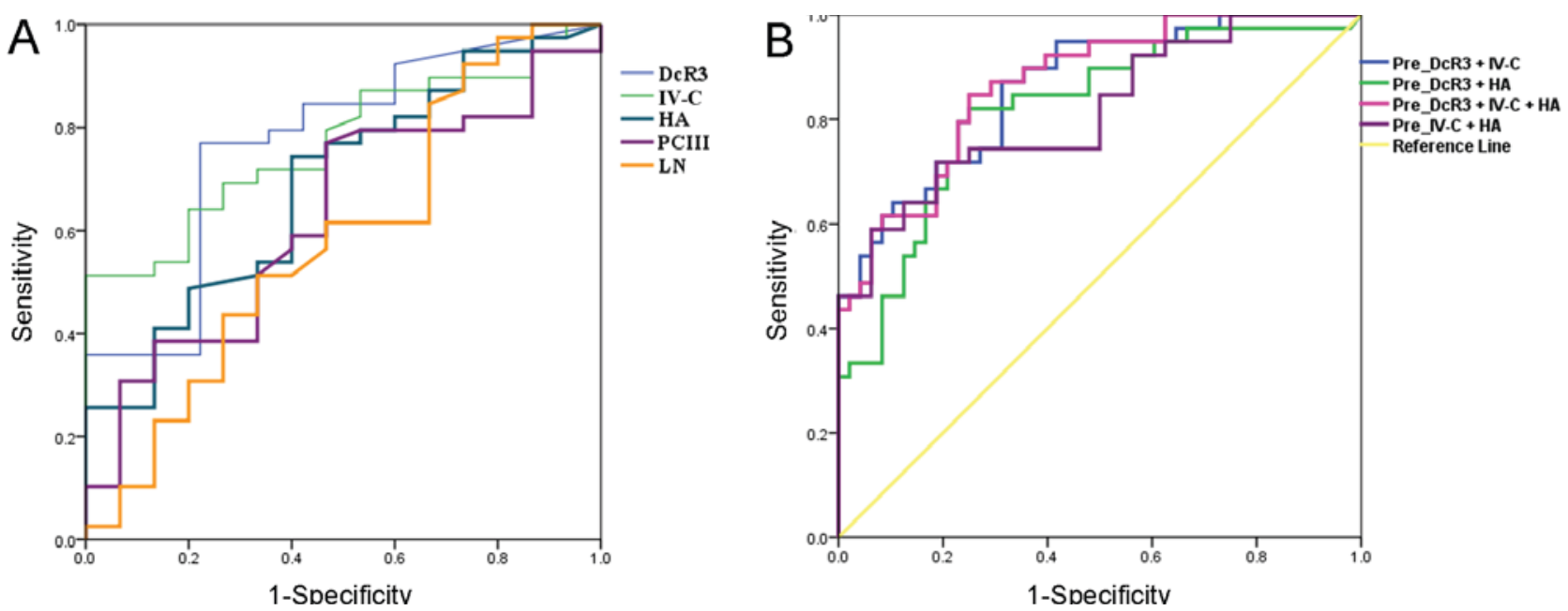

Figure 3. ROC analysis for DcR3 and DcR3 combined with other biomarkers. ROC curves were generated to evaluate the diagnostic specificity and sensitivity of DcR3 for CHB liver fibrosis. (A) ROC analysis for DcR3 in the diagnosis of CHB fibrosis. (B) ROC analysis for DcR3 combined with IV-C or HA in the diagnosis of CHB fibrosis. DcR3, decoy receptor 3; ROC, receiver operating characteristic; CHB, chronic hepatitis B; IV-C, type IV collagen; HA, hyaluronic acid; PCIII, type III procollagen; LN, laminin.

tissues, compared with normal liver tissues $(\mathrm{P}=0.021)$. DcR3 levels increased with the grade of hepatic cell carcinoma $(\mathrm{P}=0.033)$, and DcR3 mRNA was significantly higher in patients with HCC who died within 5 years, compared with those who survived $>5$ years $(\mathrm{P}=0.008$; Fig. 5$)$. Assessment of
DcR3 levels in patients with CHB associated with liver fibrosis indicated that DcR3 serves an important role in the CHB-liver fibrosis-liver cirrhosis-liver cancer progression, although the specific underlying mechanism of action requires further examination. 
Table IV. Receiver operating characteristic analysis of DcR3 for the diagnosis of chronic hepatitis B liver fibrosis.

\begin{tabular}{|c|c|c|c|c|c|c|c|}
\hline Parameters & AUC & SD error & P-value & 95\% CI lower-upper limit & Cut-off value & Sensitivity & Specificity \\
\hline DcR3 (ng/ml) & 0.807 & 0.051 & $<0.001$ & $0.688-0.887$ & 168.67 & 0.769 & 0.778 \\
\hline IV-C (pg/ml) & 0.770 & 0.053 & $<0.001$ & $0.666-0.875$ & 783.48 & 0.641 & 0.800 \\
\hline HA (ng/ml) & 0.688 & 0.058 & 0.003 & $0.575-0.801$ & 0.834 & 0.744 & 0.600 \\
\hline PCIII (ng/ml) & 0.626 & 0.062 & 0.046 & $0.504-0.749$ & 30.20 & 0.769 & 0.533 \\
\hline $\mathrm{LN}(\mathrm{ng} / \mathrm{ml})$ & 0.584 & 0.062 & 0.187 & $0.461-0.706$ & 0.097 & 0.513 & 0.667 \\
\hline DcR3+IV-C (ng/ml) & 0.862 & 0.038 & $<0.001$ & $0.786-0.937$ & 0.311 & 0.872 & 0.687 \\
\hline DcR3+HA (ng/ml) & 0.818 & 0.046 & $<0.001$ & $0.727-0.908$ & 0.388 & 0.821 & 0.750 \\
\hline DcR3+IV-C+HA (ng/ml) & 0.869 & 0.037 & $<0.001$ & $0.796-0.941$ & 0.387 & 0.846 & 0.812 \\
\hline $\mathrm{IV}-\mathrm{C}+\mathrm{HA}(\mathrm{ng} / \mathrm{ml})$ & 0.798 & 0.046 & $<0.001$ & $0.725-0.906$ & 0.471 & 0.718 & 0.750 \\
\hline
\end{tabular}

HA, hyaluronidase; PCIII, type III procollagen; IV-C, type IV collagen; DcR3, decoy receptor 3; AUC, area under the curve; CI, confidence interval; SD, standard deviation.

A

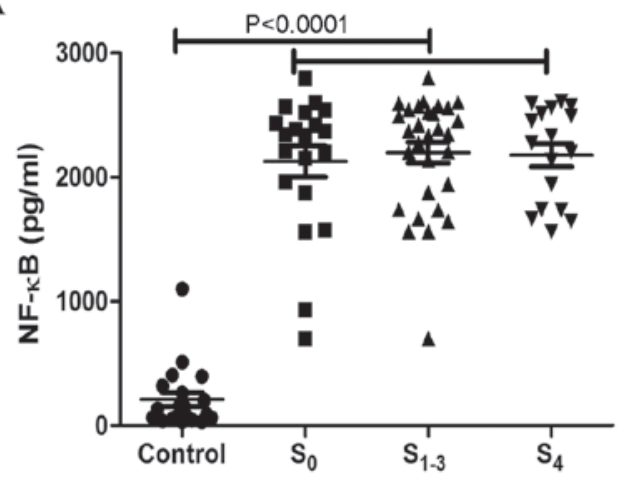

$\mathrm{B}$

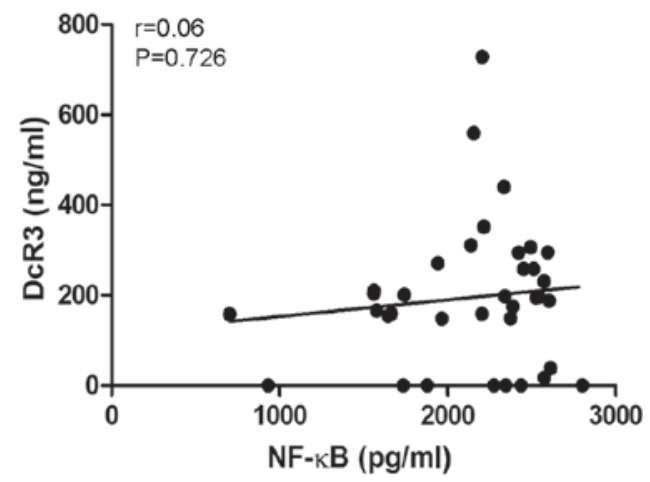

Figure 4. NF- $\kappa B$ is upregulated in patients with CHB liver fibrosis and cirrhosis. (A) NF- $\kappa$ B levels were significantly higher in $\mathrm{S}_{0}$, $\mathrm{S}_{1-3}$ and $\mathrm{S}_{4}$ groups, compared with the healthy control groups $(\mathrm{P}<0.001)$. (B) However, $\mathrm{NF}-\kappa \mathrm{B}$ levels had no association with DcR3 levels ( $\mathrm{r}=0.06, \mathrm{P}=0.726)$. $\mathrm{S}_{0}$, $\mathrm{CHB}$ without fibrosis; $\mathrm{S}_{1-3}$, $\mathrm{CHB}$ complicated with fibrosis; $\mathrm{S}_{4}$, cirrhosis; NF- $\kappa \mathrm{B}$, nuclear factor- $\kappa \mathrm{B}$; CHB, chronic hepatitis B; DcR3, decoy receptor 3.

\section{Discussion}

Accurate assessment of the degree of viral hepatic fibrosis is important for patient treatment, prognosis and surveillance. Liver biopsy, which is considered the gold standard for the diagnosis of liver fibrosis, has certain limitations. Such invasive procedures are associated with certain complications. The majority of patients refuse to undergo liver biopsy, and they are even more reluctant to accept a second liver biopsy, making it difficult to assess the efficacy of the procedure (14). Additionally, sample errors, and intraobserver or interobserver differences may affect the accuracy of the diagnostic results (15-17).

Within the TNFR family, DcR3 is the only member capable of competitively binding the three ligands TL1A, LIGHT and FasL (12). In humans, DcR3 is upregulated in pathological conditions including cancer, and autoimmune and inflammatory diseases $(18,19)$. The data from the present study demonstrated that DcR3 is highly expressed in patients with $\mathrm{CHB}$ and its expression is higher in patients with active $\mathrm{CHB}$, compared with patients who are CHB carriers. DcR3 expression was significantly associated with ALT, AST and $\gamma$-GGT. Assessment of DcR3 protein levels may provide an important diagnostic biomarker, for example for inflammatory diseases or high-grade carcinoma. The present study compared the performance of DcR3 with that of direct serological markers (HA, CIV, PCIII and LN) for the diagnosis of liver fibrosis and its stages.

In the present study, it was indicated that serum DcR3 levels were significantly increased in patients with hepatic fibrosis and hepatic cirrhosis $(\mathrm{P}<0.01)$ and significantly associated with the four indicators of hepatic fibrosis, namely HA $(\mathrm{r}=0.51, \mathrm{P}<0.0001), \mathrm{IV}-\mathrm{C}(\mathrm{r}=0.34, \mathrm{P}<0.0013)$, PCIII $(\mathrm{r}=0.49$, $\mathrm{P}<0.0001)$ and $\mathrm{LN}(\mathrm{r}=0.40, \mathrm{P}<0.0001)$, indicating the clinical value of DcR3 for the diagnosis of hepatic fibrosis. A study by Kim et al (20) on the different stages of chronic hepatitis and fibrosis determined that DcR3 expression levels were elevated in bile duct epithelial cells and infiltrating lymphocytes, in regenerated and poorly developed bile ducts, as well as in cultured hepatoma cells, indicating that DcR3 serves an important role in the progression of chronic hepatitis to hepatic fibrosis, leading to the occurrence of liver cirrhosis and HCC.

To determine the diagnostic value of DcR3 for liver fibrosis, ROC analysis was performed. The AUC values for the diagnosis of hepatitis $\mathrm{B}$ and hepatic fibrosis based on DcR3 and the four indicators of liver fibrosis, including IV-C, HA, 


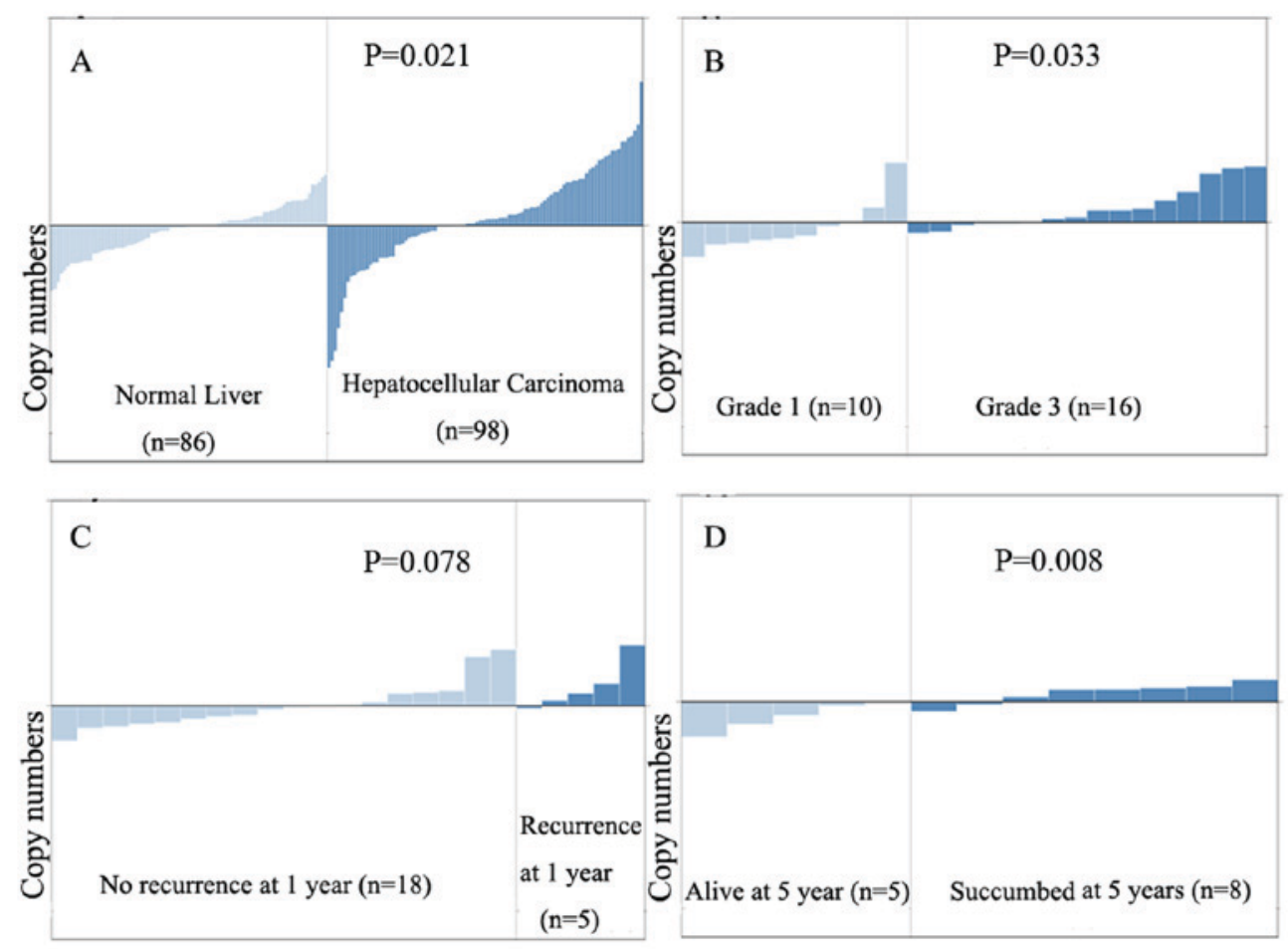

Figure 5. Oncomine software analysis of DcR3 mRNA in a public online DNA microarray database. (A) DcR3 mRNA transcript number was higher in HCC, compared with the normal liver tissues ( $\mathrm{P}=0.021)$. (B) DcR3 mRNA transcript number was higher in patients with HCC grade 3, compared with patients with HCC grade 1 ( $\mathrm{P}=0.033)$. (C) DcR3 mRNA levels in patients with recurrence or no-recurrence in 1 year $(\mathrm{P}=0.078)$. (D) DcR3 mRNA transcript number was higher in patients with HCC who succumbed prior to 5 years, compared with those who were alive following 5 years $(\mathrm{P}=0.008)$. DcR3, decoy receptor 3; HCC, hepatocellular carcinoma.

PCIII and LN, were $0.807,0.770,0.688,0.626$ and 0.584 , respectively. When IV-C and HA, which have demonstrated superior diagnostic accuracy among the four indicators, were used in combination with DcR3 as diagnostic markers, the AUC was 0.869 , with sensitivity and specificity of 84.6 and $81.2 \%$, respectively, indicating that DcR3 significantly improves the combined diagnostic value of IV-C and HA. These results indicated that the diagnostic value of DcR3 for CHB may be superior to that of the four conventional liver fibrosis indicators.

The role of DcR3 in HBV infection remains unclear. A previous study indicated that DcR3 expression is closely associated with the degree of inflammation during the pathogenetic process of acute ulcerative colitis, as increased DcR3 expression levels are observed in the peripheral blood of patients with a high incidence of inflammation, and these are significantly reduced following effective treatment (21). A previous study indicated that DcR3 is upregulated in patients with hepatitis B e antigen-negative CHB (22). However, the present study determined that the DcR3 levels are increased in patients with active hepatitis and in those with liver fibrosis. Yang et al (23) indicated that DcR3 levels were significantly increased in the sera of patients with HCC and associated with liver cirrhosis, tumor metastasis and recurrence, which indicated that the highly expressed and distributed DcR3 may serve as an important role in occurrence and development of primary HCC.

Bioinformatics analysis of a human HCC DNA microarray database indicated that DcR3 expression was significantly higher in HCC tissues compared with that in normal liver tissues. DcR3 levels increased with the grade of HCC, and the copy number of DeR3 DNA of patients with HCC who died within 5 years was significantly higher compared with that of patients with HCC who survived $>5$ years. These results indicated that DcR3 may serve as an important role in the occurrence and development of CHB, liver fibrosis, liver cirrhosis and liver cancer, although the underlying molecular mechanism requires further exploration.

The expression of DcR3 is high in patients with CHB, liver fibrosis and liver cirrhosis. However, the molecular mechanisms underlying liver cancer progression has not yet been investigated. DcR3 levels are increased in patients with inflammatory bowel disease, primary Sjogren's syndrome, rheumatoid arthritis and primary biliary cirrhosis. DcR3 is also upregulated in Kaposi's sarcoma-associated herpes virus-infected human umbilical vein endothelial cells (24) and skin lesions of psoriasis patients (25). In human keratinocytes, DcR3 is transcriptionally regulated by epidermal growth factor via the NF- $\kappa B$ signaling pathway (26). In nasopharyngeal carcinoma (NPC) cases with Epstein Barr Virus (EBV) infection, EBV binds to the promoter of the transcriptional activation factor RTA and upregulates DcR3 expression (27). Furthermore, its latent membrane protein-1 activates the NF- $\mathrm{kB}$ signaling pathway to promote DcR3 expression, and the upregulated DcR3 enhances the metastatic and invasive abilities of the NPC cell line HONE-1 (28). HBV protein HBx upregulates gene expression by binding to pattern recognition receptor at key sectors of host genes, and indirectly activates host gene promoters by interacting with the transcription factor NF- $\mathrm{kB}$ and regulating gene transcription (29). In the 
present study, the serum levels of $\mathrm{NF}-\kappa \mathrm{B}$ in patients with $\mathrm{CHB}$ were detected. The results demonstrated that NF- $\kappa \mathrm{B}$ levels were elevated in $\mathrm{S}_{0}, \mathrm{~S}_{1-3}$ and $\mathrm{S}_{4}$ groups, compared with the control group. There is no association between NF- $\kappa \mathrm{B}$ and DcR3 levels; however, the molecular mechanism underlying the role of DcR3 in the occurrence and progression from $\mathrm{CHB}$ to $\mathrm{HCC}$ remains to be elucidated.

The present study demonstrated that DcR3 is a novel indicator for the diagnosis of hepatitis B and liver fibrosis. Further in-depth study would provide indications to elucidate the underlying molecular mechanism and assist in designing strategies for the clinical treatment of liver fibrosis, liver cirrhosis and liver cancer induced by hepatitis B.

\section{Acknowledgements}

Not applicable.

\section{Funding}

The present study was supported by the Natural Science Foundation of China (grant no. 81702729), the Scientific Foundation of Shanghai Municipal Commission of Health and Family Planning (grant nos. 201540119 and 20164Y0273) and the Science and Technology Research Project of Songjiang of Shanghai (grant nos. 15SJGG25 and 15SJGG47).

\section{Availability of data and materials}

All data generated or analyzed during this study are included in this published article.

\section{Authors' contributions}

YH conceived the idea and designed the study. YH and XL contributed to the data analysis and writing of the manuscript. $\mathrm{HC}$ helped to conduct the experiments and data analysis. JZ collected clinical blood specimens and clinical data. FZ performed indicator assays. All authors read and approved the final manuscript.

\section{Ethics approval and consent to participate}

The human data reported in this manuscript were collected according to procedures approved by the Institutional Ethical Review Board of Songjiang District Center Hospital. All patients provided written informed consent.

\section{Consent for publication}

All patients provided written informed consent for the publication of their data.

\section{Competing interests}

The authors declare that they have no competing interests.

\section{References}

1. Lu FM and Zhuang H: Management of hepatitis B in China. Chin Med J (EngI) 122: 3-4, 2009.
2. Liang X, Bi S, Yang W, Wang L, Cui G, Cui F, Zhang Y, Liu J, Gong X, Chen Y, et al: EpidemiologicaI serosurvey of hepatitis B in China-declining HBV prevalence due to hepatitis B vaccination. Vaccine 27: 6550-6557, 2009.

3. Seeger C and Mason WS: Molecular biology of hepatitis B virus infection. Virology 479-480: 672-686, 2015.

4. Meng N, Gao X, Yan W, Wang M, Liu P, Lu XD, Zhang SJ, Lu YQ and Tang WX: Efficacy of telbivudine in the treatment of chronic hepatitis $b$ and liver cirrhosis and its effect on immunological responses. J Huazhong Univ Sci Technolog Med Sci 35: 230-234, 2015.

5. Neuman MG, Cohen LB and Nanau RM: Hyaluronic acid as a non-invasive biomarker of liver fibrosis. Clin Biochem 49: 302-15, 2016

6. Jiang YF, Ma J, He B, Li NP, Tang W and Gong GZ: The therapeutic effect of Anluohuaxian capsule combined with adefovir dipivoxil on patients with chronic hepatitis $B$ and influence on hepatic histology. Zhonghua Gan Zang Bing Za Zhi 20: 344-347, 2012 (In Chinese).

7. You SP, Zhao J, Ma L, Tudimat M, Zhang SL and Liu T: Preventive effects of phenylethanol glycosides from Cistanche tubulosa on bovine serum albumin-induced hepatic fibrosis in rats. Daru 23: 52, 2015.

8. Oztas E, Kuzu UB, Zengin NI, Kalkan IH, Onder FO, Yildiz H, Celik HT, Akdogan M, Kilic MY, Koksal AS, et al: Can Serum ST2 levels be used as a marker of fibrosis in chronic Hepatitis B infection? Medicine (Baltimore) 94: e1889, 2015.

9. Zhang Z, Wang G, Kang K, Wu G and Wang P: The diagnostic accuracy and clinical utility of three noninvasive models for predicting liver fibrosis in patients with HBV Infection. PLoS One 11: e0152757, 2016.

10. Lok AS and McMahon BJ: Chronic hepatitis B. Hepatology 45: 507-539, 2007

11. Hou YQ, Xu P, Zhang M, Han D, Peng L, Liang DY, Yang S, Zhang Z, Hong J, Lou XL, et al: Serum decoy receptor 3, a potential new biomarker for sepsis. Clin Chim Acta 413: 744-748, 2012.

12. Liang D, Hou Y, Lou X and Chen H: Decoy receptor 3 improves survival in experimental sepsis by suppressing the inflammatory response and lymphocyte apoptosis. PLoS One 10: e0131680, 2015.

13. Easterbrook PJ, Roberts T, Sands A and Peeling R: Diagnosis of viral hepatitis. Curr Opin HIV AIDS 12: 302-314, 2017.

14. Lambrecht J, Verhulst S, Mannaerts I, Reynaert H and van Grunsven LA: Prospects in non-invasive assessment of liver fibrosis: Liquid biopsy as the future goldstandard? Biochim Biophys Acta. 1864: 1024-1036, 2018.

15. Liu J, Ji Y, Ai H, Ning B, Zhao J, Zhang Y and Dun G: Liver shear-wave velocity and serum fibrosis markers to diagnosis hepatic fibrosis in patients with chronic vial Hepatitis B. Korean J Radiol 17: 396-404, 2016.

16. Cho HJ, Kim SS, Ahn SJ, Park JH, Kim DJ, Kim YB, Cho SW and Cheong JY: Serum transferrin as a liver fibrosis biomarker in patients with chronic hepatitis B. Clin Mol Hepatol 20: 347-354, 2014.

17. Alempijević T, Štulić M, Popovic D, Culafic D, Dragasevic S and Milosavljevic T: The role of fecal calprotectin in assessment of hepatic encephalopathy in patients with liver cirrhosis. Acta Gastroenterol Belg 77: 302-305, 2014.

18. Lin WW and Hsieh SL: Decoy receptor 3: A pleiotropic immunomodulator and biomarker for inflammatory diseases, autoimmube diseases and cancer. Biochem Pharmacol 81: 838-847, 2011.

19. Siakavellas SI, Sfikakis PP and Bamias G: The TL1A/DR3/DcR3 pathway in autoimmune rheumatic diseases. Semin Arthritis Rheum 45: 1-8, 2015.

20. Kim S, Kotoula V, Hytiroglou P, Zardavas D and Zhang L: Significance of increased expression of decoy receptor 3 in chronic liver disease. Dig Liver Dis 41: 591-598, 2009.

21. Bamias G, Kaltsa G, Siakavellas SI, Papaxoinis K, Zampeli E, Michopoulos S, Zouboulis-Vafiadis I and Ladas SD: High intestinal and systemic levels of decoy receptor 3 (DcR3) and its ligand TL1A in active ulcerative colitis. Chin Immunol 137: 242-249, 2010.

22. Hou Y, Xu P, Lou X, Liang D, Zhang M, Zhang Z and Zhang L: Serum decoy receptor 3 is a useful predictor for the active status of chronic hepatitis B in hepatitis B e antigen-negative patients. Tohoku J Exp Med 230: 227-232, 2013.

23. Yang M, Chen G, Dang Y and Luo D: Significance of decoy receptor 3 in sera of hepatocellular carcinoma patients. Ups J Med Sci 115: 232-237, 2010. 
24. Yoo S, Jang J, Kim S, Cho H and Lee MS: Expression of DcR3 and its effects in kaposi's sarcoma-associated herpesvirus-infected human endothelial cells. Intervirology 55: 45-52, 2012.

25. Bamias G, Evangelou K, Vergou T, Tsimaratou K, Kaltsa G, Antoniou C, Kotsinas A, Kim S, Gorgoulis V, Stratigos AJ and Sfikakis PP: Upregulation and nuclear localization of TNF-like cytokine 1A (TL1A) and its receptors DR3 and DcR3 in psoriatic skin lesions. Exp Dermatol 20: 725-731, 2011.

26. Hsieh SL and Lin WW: Decoy receptor 3: An endogenous immubomudulator in cancer growth and inflammatory reactions. J Biomed Sci 24: 39, 2017.

27. Ho CH, Hsu CF, Fong PF, Tai SK, Hsieh SL and Chen CJ: Epstein-Barr virus transcription activator Rta upregulates decoy receptor 3 expression by binding to its promoter. J Virol 81: 4837-4847, 2007.
28. Ho CH, Chen CL, Li WY and Chen CJ: Decoy receptor 3, upregulated by Epstein-Barr virus latent membrane protein 1, enhances nasopharyngeal carcinoma cell migration and invasion. Carcinogenesis 30: 1443-1451, 2009.

29. Xia L, Tian D, Huang W, Zhu H, Wang J, Zhang Y, Hu H, Nie Y, Fan D and Wu K: Upregulation of IL-23 expression in patients with chronic hepatitis $\mathrm{B}$ is mediated by the $\mathrm{HBx} / \mathrm{ERK} / \mathrm{NF}-\kappa \mathrm{B}$ pathway. J Immunol 188: 753-764, 2012. 